\title{
High Agatston aortic valve calcium score predicts transcatheter paravalvular aortic regurgitation
}

\author{
Kevin L. Greason, MD, Eric E. Williamson, MD, Rakesh M. Suri, MD, and Verg Mathew, MD, Rochester,
} Minn

Paravalvular aortic regurgitation is common after transcatheter valve replacement. ${ }^{1}$ Importantly, even mild regurgitation is associated with reduced survival. We hypothesized that there is a direct correlation between high Agatston aortic valve calcium score and the prevalence of transcatheter paravalvular aortic regurgitation.

\section{MATERIALS AND METHODS}

We reviewed the records of 303 patients who underwent transcatheter aortic valve replacement with the SAPIEN/SAPIEN XT valve (Edwards Lifesciences Corporation, Irvine, Calif) from November 2008 through August 2013. From this population, a study group was created of the 99 patients $(32.9 \%)$ who underwent preopertive contrast-enhanced multidetector computed tomography with calculation of the Agatston aortic valve calcium score and aortic valve area.

Categoric data are presented as counts with frequencies, and continuous data are presented as medians with interquartile ranges (IRQs). Transcatheter aortic valve oversize data are reported as percentages and were determined by the following formula: [(transcatheter aortic valve area/contrast-enhanced multidetector computed tomographically derived aortic valve area) -1$] \times 100$. Logistic regression of dichotomous variables was done using the upper interquartile range Agatston score and lower interquartile range valve oversize calculation. Analysis was completed using JMP 10.0 software package (SAS Institute Inc, Cary, NC).

\section{RESULTS}

Median age of the patients was 82 years (IRQ, 77-87 years), 51 patients were male $(51.5 \%)$, and Society of Thoracic Surgeons predicted risk of mortality was $8.1 \%$ (IRQ, 5.8\%-10.8\%). Important findings included an Agatston aortic valve calcium score of 2386 (IRQ, 1592-3342) and a transcatheter aortic valve oversize of $10.4 \%$ (IRQ, $3.75 \%-18.6 \%)$. Vascular access was transapical in 56 patients $(56.6 \%)$, transfemoral in $35(35.4 \%)$, and transaortic in $8(8.1 \%)$.

Transcatheter paravalvular aortic regurgitation occurred in 62 patients $(62.6 \%)$. Specific grades of regurgitation were none in 36 cases $(36.3 \%)$, trivial in $26(26.3 \%)$, mild in $26(26.3 \%)$, moderate in $9(9.1 \%)$, and severe in $2(2 \%)$. Study groups were created that included nonsignificant regurgitation (grade none or trivial) in 62 patients $(62.6 \%)$ and significant regurgitation (grade mild, moderate, or severe) in 37 patients $(37.4 \%)$.

The median Agatston aortic valve calcium score was lower in the nonsignificant regurgitation group (2212) than in the significant regurgitation group (2685; $P=.015)$. In addition, transcatheter aortic valve oversize was greater in the nonsignificant regurgitation group $(12.9 \%)$ than in the significant regurgitation group $(8.2 \%$; $P=.016)$.

Logistic regression analysis identified an increased risk of significant regurgitation in patients with an Agatston aortic valve calcium score greater than the overall upper IRQ of 3342 (odds ratio, 3.17; 95\% confidence interval, 1.24-8.38; $P=.016)$. There was no increased risk of significant regurgitation in patients with a transcatheter aortic valve oversize of less than $3.75 \%(P=.100)$.

\section{DISCUSSION}

Agatston aortic valve calcium score is predictive of significant regurgitation after SAPIEN or SAPIEN XT transcatheter aortic valve replacement. Other investigators support this association, although a score break point at which increased risk of regurgitation occurs has not been well established. ${ }^{2}$ On the basis of our current data and analysis, a break point of an Agatston aortic valve calcium score of 3342 (the overall upper IRQ) seems reasonable for study in further investigations.

\section{References}

1. Kodali SK, Williams MR, Smith CR, Svensson LG, Webb JG, Makkar RR, et al Two-year outcomes after transcatheter or surgical aortic-valve replacement. N Engl J Med. 2012;366:1686-95.

2. Ewe SH, Ng AC, Schuijf JD, van der Kley F, Colli A, Palmen M, et al. Location and severity of aortic valve calcium and implications for aortic regurgitation after transcatheter valve implantation. Am J Cardiol. 2011;108:1470-7.

\footnotetext{
From the Mayo Clinic, Rochester, Minn.

Disclosures: Authors have nothing to disclose with regard to commercial support.

Received for publication Jan 28, 2014; accepted for publication Feb 14, 2014;

available ahead of print March 15, 2014.

Address for reprints: Kevin L. Greason, MD, Division of Cardiovascular Surgery,

Mayo Clinic, Rochester, MN 55905 (E-mail: greason.kevin@mayo.edu).

J Thorac Cardiovasc Surg 2014;147:1991

$0022-5223 / \$ 36.00$

Copyright (c) 2014 by The American Association for Thoracic Surgery

http://dx.doi.org/10.1016/j.jtcvs.2014.02.048
} 